Bond University

Research Repository

\title{
The contemporary management of neck pain in adults
}

Fandim, Junior V; Nitzsche, Renato; Michaleff, Zoe A; Pena Costa, Leonardo Oliveira; Saragiotto, Bruno

Published in:

Pain Management

DOI:

10.2217/pmt-2020-0046

Licence:

Other

Link to output in Bond University research repository.

Recommended citation(APA):

Fandim, J. V., Nitzsche, R., Michaleff, Z. A., Pena Costa, L. O., \& Saragiotto, B. (2021). The contemporary management of neck pain in adults. Pain Management, 11(1), 75-87. https://doi.org/10.2217/pmt-2020-0046

\footnotetext{
General rights

Copyright and moral rights for the publications made accessible in the public portal are retained by the authors and/or other copyright owners and it is a condition of accessing publications that users recognise and abide by the legal requirements associated with these rights.
}

For more information, or if you believe that this document breaches copyright, please contact the Bond University research repository coordinator. 


\title{
The contemporary management of neck pain in adults
}

\section{PRACTICE POINTS}

- Neck pain is an important public health problem with high levels of disability worldwide.

- The prognosis of neck pain is favourable for the first six weeks with significant reduction in pain intensity and disability.

- A large proportion of people with neck pain tend to develop chronic or persistent symptoms.

- Best evidence supports non-pharmacological interventions (eg, exercise, manual therapy and education) instead of pharmacological interventions for the management of neck pain.

- Our findings are limited by the small number of studies and poor methodological quality.

\begin{abstract}
Neck pain is a common condition with a high prevalence worldwide. Neck pain is associated with significant levels of disability and is widely considered an important public health problem. Neck pain is defined as pain perceived between the superior nuchal line to the spinous process of the first thoracic vertebra. In some types of neck conditions, the pain can be referred to the head, trunk and upper limbs. This perspective article aims to provide an overview of the available evidence on prevalence, costs, diagnosis, prognosis, risk factors, prevention and management of patients with neck pain.
\end{abstract}




\section{Epidemiology and costs}

According to the Global Burden of the Disease, neck pain is ranked fourth in terms of years lived with disability globally [1]. The point prevalence of neck pain is estimated as $8 \%$ [2], the 1 -month prevalence is $23 \%$, the 1-year prevalence is $37 \%$, and finally, the lifetime prevalence can be as high as $48 \%$ [2]. The overall prevalence of neck pain tends to be higher in women than men across all ages groups [3]. The peak prevalence of neck pain occurs between 45-49 years in males (about 9 per 100,000 inhabitants) and between 45-54 years in females (about 13 to per 100,000 inhabitants) [3]. High-income countries tend to have higher prevalence rates than low- and middle-income countries [3,4]. One possible explanation for this would be the greater number of elderly, obese and sedentary people in high-income countries [3]. We also observed a higher prevalence of neck pain in urban areas than rural areas [4].

The prevalence of neck pain has also been found to be higher in the working population, with those employed in sedentary office-based roles at particularly higher risk than the general population [5]. Neck pain can result in activity limitations including reduced neck range of motion, sitting tolerance, sleep disturbance, reduced quality of life and is associated with work absenteeism [6-8]. It has an enormous economic impact due to health care costs, decreased productivity or absence from work, and expenses with work insurance [9, 10]. Patients with neck pain are responsible for an average of $11 \%$ of the visits to rehabilitation centres in the United States [11]. An estimate from the Netherlands demonstrated a total cost for neck pain of US\$ 686 million annually (of which 23\% was direct costs and $77 \%$ indirect costs). In the United States, it is estimated that between 1999 and 2008 there was an increase in annual spending on care related to low back and neck pain by around USD \$ 487-950 per patient. In 2016 low back pain and neck pain had the highest health care costs between 154 conditions in the United States, with a total spending estimated of USD $\$ 134,5$ billion, in which $57.2 \%$ was made by the private insurance, $33.7 \%$ by public insurance and $9.2 \%$ by out-of-pocket payments[12]. In addition, neck pain ranks second in the ranking of labour compensation in the USA [13].

\section{Classification of neck pain}

Neck pain can be classified based on the duration of symptoms, the pain pattern and the pain mechanism [13-15]. Similar to other musculoskeletal conditions, the duration of symptoms is classified as acute (up to 6 weeks), subacute (between 6 to 12 weeks) and chronic (greater than 12 weeks) [13]. The pattern of neck pain is classified into a single episode (i.e., without history 
of pain and full recovery after the episode), recurrent (i.e., two or more episodes with full recovery between them) and persistent (i.e., without periods of full recovery) [14]. Finally, the pain mechanism is classified as specific (i.e., when it has an identifiable pathoanatomical cause of pain), neuropathic (originated by compression or lesion of the peripheral nervous system, such as cervical radicular syndrome [16]) and non-specific (or idiopathic i.e. not attributed to a tissue damage or specific pathology) $[14,15,17,18]$.

Whiplash associated disorders (WADs) is the term used to described bony or soft tissue injuries that occur due to a 'sudden acceleration-deceleration energy transfer to the neck', most commonly the result of a motor vehicle accident, sports falls and others physical trauma [1921]. The diagnosis of WADs essentially describes a specific mechanism of injury and currently the pathophysiology underpinning the disorder are not well understood. WADs are associated with a variety of symptoms including neck pain, headache, dizziness, visual and auditory disturbance. As a result, WADs are most commonly classified using the Quebec Task Force grading system based on the severity of presenting signs and symptoms: Grade 1: neck complaint, stiffness, or tenderness with no physical signs; Grade 2: neck complaint with musculoskeletal signs including decreased range of motion and point tenderness; Grade 3: neck complaint with neurologic signs, such as sensory deficits, decreased or absent deep tendon reflexes, muscle weakness; Grade 4: neck complaint with fracture or dislocation [22].

Further classifications used in the neck pain field include those made by the "international statistical classification of diseases and related health problems" (ICD), and the "associated international classification of functioning, disability an health (ICF) [16]. Classifications based on clinical findings are also commonly used in the neck pain field. The clinical practice guidelines from the Neck Pain Task Force [9] recommends the classification of neck pain in a four-degree system: i) no signs or symptoms suggestive of major structural pathologies and minor interference on daily activities; ii) no signs or symptoms suggestive of major structural pathologies with major interference in daily activities; iii) no signs or symptoms suggestive of major structural pathologies, but presence of neurological signs, such as decreased reflexes and weakness; and iv) signs or symptoms of major structural pathologies, such as possible red flags. A 2017 clinical practice guideline for physical therapists [13] suggests a slightly different classification but still into four categories: i) neck pain with mobility deficit; ii) neck pain with movement coordination dysfunction (includes whiplash-associated disorder); iii) neck pain with headache (cervicogenic headache); iv) neck pain with radiating pain (neurological signs) [13]. Both clinical practice guidelines suggest that treatment should be performed according to 
these categories. However, we have not yet found randomized controlled trials that support the use of some of these classifications based on clinical findings to guide treatments in this population. In addition a 2020 systematic review showed that treatment-based classification systems was not more effective than alternative treatments [23].

\section{Assessment and diagnosis}

\section{Diagnostic triage}

Initial assessment of a person presenting with neck pain should begin with obtaining a thorough history of the presenting complaint and physical examination (including neurological examination). The clinical history would include obtaining information about the symptoms including radiation of pain or other symptoms such as weakness, dizziness, pain patterns, onset of symptoms including mechanism of injury, aggravating and easing factors and identification of red flags such as trauma.

\section{Neck pain following trauma}

A person presenting with neck pain following trauma should undergo additional assessment to ensure they have not sustained a serious cervical spine injury e.g., cervical spine fracture, dislocation or ligamentous instability which would require specific management such as surgery. The Canadian cervical spine rule is a clinical prediction rule that is designed to support clinical decision making in low risk patients (alert [Glasgow scale $=15$ ], stable and under 65 years old) who present following blunt trauma[24]. This clinical prediction rule assess the need for imaging to rule out important neck spine injuries [25]. Computed tomography is the first choice exam of severe neck trauma in high risk patients (Glasgow $\leq 14)[26,27]$. In polytrauma patients, neck computed tomography is the first choice exam [28] and nuclear magnetic resonance contributes to the differential diagnosis for soft tissue injuries or neck spinal cord injury [28].

\section{Screening for red flags}

In the clinical evaluation we can also recognize red flags that may indicate the presence of serious pathologies [15] which include [9, 17]: fractures, vertebral dislocation, dissection of the vertebral artery, spinal cord injury, cervical myelopathy, infection, neoplasia and systemic diseases such as inflammatory arthropathies. The signs and symptoms frequently considered as red flags are [9, 15]: age under 20, age over 50 with concomitant vascular disease, signs of 
neurological deficits, altered laboratory tests (erythrocyte sedimentation rate, level of reactive protein $\mathrm{C}$, white blood cells), trauma, previous neck surgery, history of intravenous drug use, signs and symptoms of fever, neck stiffness, pain that does not improve regardless of the therapy used, nausea or vomiting, unexplained weight loss, excessive sensitivity to palpation of the vertebral body, severe tenderness in the neck.

The diagnostic accuracy in identifying serious diseases through the presence of red flags in patients with neck pain has not yet been validated [15, 29]. Some authors even suggest that serious neck conditions are rarely found to be associated with red flags [15, 30]. Therefore, it is recommended to monitor patients who present with one or more red flags in terms of changes/worsening of symptoms or presentation of new symptoms such as muscle weakness. Additional assessment may also be indicated, such as neurological examination (on neurological deficits), in the presence of fever (due to suspected infection) and trauma (due to the possibility of major structural injuries).

If neck pain (initial or progressively worsening) is not traumatic, complementary imaging tests will be indicated in some specific situations [29]: in suspected infection (due to the presence of fever associated with changes in laboratory test results), it is indicated nuclear magnetic resonance with or without contrast; in known malignancy. Nuclear magnetic resonance with or without contrast is also indicated for patients who have undergone previous surgeries, mainly in anterior cervical discectomy and fusion (due to the suspicion of pseudoarthrosis or problems with internal fixators), neck radiography and neck computed tomography without contrast are also indicated. The diagnosis of important diseases or neck spine injuries made through imaging is essential to guide medical practice.

\section{Idiopathic neck pain}

The use of imaging in people with idiopathic neck pain is rarely indicated. Many clinicians often relate the cause of neck pain with the degenerative changes in neck spine structures found in imaging studies. However, several neck changes are found in imaging studies in asymptomatic people and tend to increase with aging [31-37]. These findings include disc degeneration, disc protrusion, disc bulging, disc space narrowing, decrease in disc signal intensity, spinal cord compression, foraminal stenosis, decreased sagittal diameter and axial area of the dural tube and spinal cord. Therefore, in most cases, we should not relate these 
radiological findings to neck pain [13]. It avoids a possible nocebo, in which verbal information from the health professional could generate a negative expectation in the patient [38].

\section{Outcome measures}

Currently, there is no core set outcomes recommended for the assessment of people with neck pain. Recent clinical practice guideline recommend clinicians to assess pain intensity, physical function and psychological aspects related to pain (e.g., anxiety, depression, catastrophization) [13]. Health-related quality of life, work status and interference of pain can complement the assessment of people with neck pain [39-41].

Pain intensity is commonly measured by the Numeric Pain Rating Scale (NPRS), ranging from 0 (no pain) to 10 (worst pain) points. The NPRS has moderate reliability for non-specific neck pain with an Intraclass Correlation Coefficient (ICC) of 0.67; (95\% CI: 0.27 to 0.84) [42], and neuropathic neck pain (ICC: 0.58 ; 95\% CI: 0.14 to 0.79 ) [43] and excellent reliability for cervicogenic headache (ICC: $0.92 ; 95 \%$ CI: 0.46 to 0.97 ) [44]. For disability, the Neck Disability Index (NDI) [45] is the most popular and recommended outcome measure. A 2019 systematic review [46] suggested that the NDI has excellent reliability for a 1-week test-retest interval (ICC: $0.92 ; 95 \%$ CI: 0.85 to 0.96 ). Other common measures include: the "hospital anxiety and depression scale" (HADS) (assess anxiety and depression) [47, 48]; the "pain catastrophizing scale" (PCS) (a self-report measure of catastrophizing in non-clinical and clinical population) [49]; the Tampa scale of kinesiophobia (measure the fear of movement related to pain) [50]; the short form 12 health survey [51] and EQ-5D-3L (measure quality of life) [52]; and brief pain inventory (BPI) (measure intensity of pain) [53]

\section{Risk Factors}

\section{General Risk factors for a first episode of neck pain}

A 2018 systematic review synthesized the information on the risk factors related to the development of an episode of neck pain [54]. This systematic review included 10 longitudinal studies ( $\mathrm{n}=19,055$ participants) and classified the risk factors according to the strength of the association, with little association (relative risk or odds ratio between 1.0 to 1.5), moderate association (relative risk or odds ratio between 1.5 to 2.0) and high association (relative risk or odds ratio greater than 2.0) $[54,55]$. The level of association between individual, physical and psychological risk factors varied from moderate to high association [54]. The authors observed 
that high body mass index (> $\left.30 \mathrm{~kg} / \mathrm{m}^{2}\right)(\mathrm{OR}: 2.21 ; 95 \% \mathrm{CI}: 1.32$ to 3.70$)$, having history of neck pain (OR: $2.24 ; 95 \%$ CI: 1.39 to 3.06) and high perception of muscle tension (relative risk (RR): $4.04 ; 95 \%$ CI: 1.99 to 8.17 ) were risk factors with a high association for a neck pain episode. Further, risk factors such family size (composed of three people (RR: 1.50; 95\% CI: 1.10 to 2.10 ), being male with low income (OR: 1.8; 95\% CI: 1.10 to 2.70 ) and high perceived economic stress with low income (OR: $2.00 ; 95 \%$ CI: 1.30 to 3.20$)$ were moderate risk factors. On the other hand, the authors also observed that leadership profile (OR: 0.32; 95\% CI: 0.16 to 0.67), pleasant social environment (OR: 0.45 ; $95 \%$ CI: 0.25 to 0.83 ), leisure physical activity (OR: 0.6; 95\% CI: 0.4 to 0.9) and good resistance of the extensor muscles (OR: 0.92; 95\% CI: 0.87 to 0.97 ) were all protective factors. The authors conclude that most of the factors analysed are considered modifiable, and this result could possible contribute to a potential social impact. A 2019 systematic review ( 8 studies $n=3,345$ ) [56] observed that people who have suffered acute neck injury due to vehicular accident, have an increased risk of developing neck pain (RR: 2.3 ; 95\% CI: 1.8 to 3.1). Table 1 present a summary of the available evidence on the risk factors for neck pain.

Furthermore, there are increasing interest to identify risk factors for neck pain in young adults. A 2020 systematic review investigated the risk factors for non-specific neck pain in young adults [57]. This systematic review included 6 studies $(n=8,856$ participants) identifying a total of 56 risk factors in young adults on 18-29 years of age. The authors observed that 56 risk factors assessed were covered on all ICF components such as, 24 risk factors (body functions and structures), 15 risk factors (activities and participation), 10 risk factors (environmental), 10 risk factors (personal factors), and female sex, BMI, perceived stress, duration of daily computer and physical activity were risk factors assessed in more than one study. There is very low to low quality of evidence that perceived stress (OR: 1.7; 95\% CI: 1.1 to 2.6), utilizing a computer for at least two 4 hour with no break (OR: 1.8; 95\% CI: 1.2 to 2.9), computer screen not adjusted at eye level (OR: 1.6; 95\% CI: 1.1 to 2.4), keyboard positioned too high (OR: 2.2; 95\% CI: 1.2 to 3.9$)$ and $2^{\text {nd }}$ year students (versus $1^{\text {st }}$ year) (OR: $1.9 ; 95 \%$ CI: 1.1 to 3.4 ) are associated with developing a first episode of neck pain. Female gender demonstrated inconsistent results between three studies, and high body mass index, physical activity level, utilizing computer for neither less nor more than 3 hour per day are not associated with developing a first episode of neck pain. The authors emphasize the number of studies assessing potential risk factors with spurious findings are worrying, and the need for more high-quality studies. 


\section{Prognosis}

There is a lack of high-quality prognostic studies in patients with neck pain $[58,59]$. The latest systematic review summarized the evidence related to the prognosis of patients with acute nonspecific neck pain [58]. This review included three cohort studies and three randomized controlled trials (pooled $n=283$ participants) [58]. The authors observed a significant reduction in pain intensity and disability in the first six weeks after the onset of symptoms. The mean reduction in pain intensity in the first six weeks was 35 points (95\% CI: 32 to 38) and the mean reduction in disability in the six weeks was 17 points (95\% CI: 15 to 19), both measured on 0100 scales. From six to 52 weeks, pain intensity tends to increase and those patients who did not recover are more likely to develop chronic neck pain [58]. In addition, data from an inception cohort study show that about half of the patients will fully recover up to 12 months [60]. Residual symptoms and recurrences between one to five years of initial episode are seen in $50 \%$ to $85 \%$ of patients, respectively $[15,61,62]$. The current evidence on prognosis shows that patients with neck pain have a favourable initial clinical course, but there is a significant burden on patients over time [58-60].

\section{Prognostic factors}

Several studies have investigated prognostic factors and their influence on the clinical course of patients with neck pain [60,63-65]. A systematic review with six prospective longitudinal studies, (pooled $n=2,446$ participants) investigated the prognostic factors for persistent nonspecific neck pain after a first episode [66]. The authors summarised the overall quality of evidence for pain intensity and perceived non-recovery at three, six and 12 months [66]. The authors found very low to low quality of evidence that male gender (OR: 3.1; 95\% CI: 1.5 to 6.7), presence of kinesiophobia (OR: 1.09; 95\% CI: 1.02 to 1.15 ), co-existing low back pain (OR: 1.6; 95\% CI: 1.1 to 2.2) and age between 45 and 59 years (OR: 3.9; 95\% CI: 2.2 to 6.7) are associated with a worse prognosis in terms of pain intensity. Low quality of evidence was found for prognostic factors associated with non-recovery; these were previous neck pain (OR: 1.67; $95 \%$ CI: 1.25 to 2.24 ), co-existing low back pain (OR: 2.29 ; 95\% CI: 1.27 to 4.12 ) and neck pain accompanied by headache (OR: 3.33; 95\% CI: 1.35 to 8.33) [66]. Table 2 presents a synthesis of the evidence on prognostic factors in non-specific neck pain. Verwoerd et al. [66] identified a number of key limitations in the available literature that impact on our current understanding of the prognosis and prognostic factors associated with persistent neck pain. These include variability in the definition of neck pain, poor description of prognostic factors 
and poor methodological quality of the included studies [66]. Thus, more high-quality studies using standardised definitions are needed to better understand the prognostic factors for neck pain in the population.

\section{Interventions to prevent neck pain}

Relatively few studies have investigated the effectiveness of prevention strategies for nonspecific neck pain and these present conflicting findings [67-70]. The most recent systematic review (five studies, $\mathrm{n}=3,852$ ) summarized the evidence related to the effectiveness of interventions that aim to prevent a new episode of neck pain [71]. The authors found two main approaches were used to prevent a new episode of neck pain; ergonomic programs (e.g., adjustment of workstation) and exercise programs (e.g., usual aerobic exercise). Very lowquality evidence suggested that there is no difference between an ergonomic program compared to minimal or no intervention in prevent new neck pain episodes (OR: $1.00 ; 95 \%$ CI: 0.74 to $1.35, \mathrm{n}=3$ trials). However, there is moderate quality evidence that an exercise program is better than no intervention control in reducing the risk of a new episode of neck pain (OR: 0.32; 95\% CI: 0.12 to $0.86, n=2$ trials). The authors conclude that these findings are based upon a low number of trials, most of which were conducted office workers, so additional high-quality trials are needed to strengthen these estimates. Since this systematic review was published, a recent randomized controlled trial [72] investigated a multifaceted intervention (i.e., participatory ergonomics to tailed case management program) for the prevention of musculoskeletal pain in nursing staff. The authors found that multifaceted intervention was effective compared to care as usual to reduce the risk of self-perceived of neck, shoulder and upper back pain in nursing staff (OR: 0.37; 95\% CI: 0.14 to 0.96). Further, Sitthipornvorakul et al [70] investigated the effects of a walking intervention compared to no intervention in reducing the risk of a new episode of neck pain in office workers in a period of 6 months. These authors observed a positive effect of walking intervention (OR: 0.22 ; 95\% CI: 0.06 to 0.75 ). Further studies are needed to investigate prevention of neck pain episodes. This evidence will allow prioritising the allocation of resources to prevention programs with known effectiveness which may have a substantial impact on reducing treatment costs and improving the quality of life and productivity of people for whom the program worked.

\section{Treatments}


The goal of treatment for people with neck pain is to reduce pain intensity and disability over time. Clinical practice guidelines use different classification systems to guide management of patients with neck pain $[13,73,74]$. The most known are risk stratification based systems that classify patients based on their risk of persistent pain (e.g. low, medium and high risk) [13, 73]. Regardless the approach used, guidelines recommend advice or education for most patients who are considered to be at low risk of chronicity in the acute phase[13, 73, 74]. This recommendation is in line with the expected course of improvement of pain and activities, and it would be expected that these patients do not require additional treatments [73]. Patients with medium or high risk for chronicity could benefit from more complex treatments combined with low-level pharmaceuticals [13, 73]. Generally, this management treatments includes nonpharmacological interventions (e.g., education, exercise, manual therapy, physical agents or multimodal approach), with the addition of pharmacological interventions as required (e.g., non-steroidal anti-inflammatory drugs) $[13,73]$. Thus, as first line all guidelines focus primarily on non-pharmacological interventions neck pain patients (exception to know disease) [13, 73, 74].

\section{Pharmacological interventions: Evidence acute/subacute/chronic}

Guidelines recommend the use of pharmacological interventions for refractory presentations, be used over a short period and as an adjunct to other non-pharmacological treatments. Judicious use of non-opioid based analgesics (e.g. nonsteroidal anti-inflammatory drugs) should be considered as first line therapy. [75-81]. These recommendations are based on limited evidence and with consideration of the harms associated with opioid based analgesics.

Current evidence for pharmacological interventions is as follows. There is moderate evidence that intravenous methylprednisolone is effective in reducing pain intensity compared to placebo for patients with acute whiplash at one week [82]. There is moderate quality of evidence that nonsteroidal anti-inflammatory drugs (NSAIDs) are effective in reducing pain intensity compared to placebo for patients with neck pain at immediate term [83]. There is also moderate evidence that intramuscular lidocaine and neck stretching are effective for reducing pain compared to neck stretches alone for chronic neck pain at three months [82]. On the other hand, there are high quality of evidence that botulinum toxin type A have similar effects for reducing pain intensity compared to placebo for chronic neck pain at short term [84]. The majority of the studies in the area were designed to assess the effects of non-pharmacological treatments in neck pain patients. 


\section{Non-pharmacological treatments: Evidence acute/aubacute/chronic}

With regards to physical therapy-based interventions, there is moderate quality evidence that manipulation alone is effective for reducing pain intensity and function compared to oral medication (e.g., NSAIDs and opioids) for acute/subacute neck pain at short term [78]. There is low quality evidence that exercises (stretching and strengthening) are effective for reducing pain than waiting list for patient acute radiculopathy patients at short term [77]. Further, there is low quality evidence that motor control exercises have similar effects for reduction pain intensity compared to other interventions for patients with chronic neck pain [85]. Thus, there is moderate quality evidence that exercises (stabilization and strengthening) are effective for reducing pain and improving function than waiting lists controls for patients with chronic neck pain [77]. Passive therapies, such as electrotherapy (EMS and TENS) had very low evidence of no difference from placebo interventions [79].

\section{Psychological treatments: Evidence Acute/Subacute/chronic}

With regards to psychological interventions, there is low quality evidence that psychological therapies (e.g., cognitive behavioural treatment) are effective for reducing pain intensity than other interventions in subacute neck pain [80]. Further, there is low quality evidence that psychological therapies are effective for reducing pain intensity and improving function when compared to other interventions or no treatment controls in subacute and chronic neck pain [80]. There is low quality evidence that self-management strategies have similar effects for improving function than advice on stretching [76].

\section{Education: Evidence acute/subacute/chronic}

With regards to patient education (advice), there is moderate quality evidence that patient education (educational video advice) is effective for reducing pain intensity than no treatment in acute whiplash patient at short term [76]. On the other hand, there is very low quality evidence that patient education (self-care strategies) have similar effect than no treatment in acute to chronic mechanical pain patient at short term [76].

Table 3 presents a summary of the available evidence for treating neck pain. At the moment, healthcare professionals should use the available evidence to assist in the decision-making process [86-88]. A multimodal approach should be interesting for patients with neck pain considering systematic reviews and guidelines to different neck pain disorders. 


\section{Future perspective}

Our current understanding of the causes, prognosis, prevention and treatment of neck pain is limited by the relatively small number of studies and their poor methodological quality. There is particular need for research to better elucidate the pain mechanisms involved in the development of non-specific neck pain, research on the effectiveness of interventions designed to prevent and treat neck pain, and research to enable the early identification of those at risk of poor prognosis or non-recovery. In 2019, an international Delphi study was conducted to identify The New Agenda for Neck Pain Research. This resulted in the identification of 5 priority areas for neck pain research, specifically: 1) to establish the effectiveness and costeffectiveness of available treatments, 2) translate research evidence into clinical settings, 3) identify the effectiveness of education and self-care in prevention and treatment, 4) identify causal factors for the development of neck pain, and 5) define the natural course and prognostic factors for people with neck pain [89]. Researchers and funding agencies can use this new agenda to direct research efforts towards answering the most important questions identified in the field of neck pain. In the absence of robust evidence, this leaves clinicians to use indirect or empirical evidence to guide their clinical decisions. 
Table 1. Risk factors for an episode of neck pain

\begin{tabular}{l} 
Risk factors \\
\hline BMI $\left(>30 \mathrm{~kg} / \mathrm{m}^{2}\right)[54]$
\end{tabular}

Estimate (95\% CI)

High perceived economic stress (low income) [54]

OR 2.21 (1.32 to 3.70)

Marital status (widowed) [54]

OR 2.00 (1.30 to 3.20 )

Male (low income) [54]

RR 1.80 (1.10 to 2.80 )

Family size (four people) [54]

OR 1.8 (1.10 to 2.70$)$

RR 1.70 (1.20 to 2.40 )

Family size (three people) [54]

RR 1.50 (1.10 to 2.10)

Work at computer (for at least two 4 hour with no

OR 1.8 (1.16 to 2.89$)$

break) [57]

Computer screen (not adjusted at eye level) [57]

OR 1.64 (1.13 to 2.36$)$

Keyboard position close to the body [90]

RR 1.46 (1.07 to 1.99 )

Keyboard position (high) [57]

OR 2.18 (1.21 to 3.91

Adjust sitting position [54]

OR 1.80 (1.16 to 2.81$)$

Awkward positions [54]

OR 1.65 (1.04 to 2.60)

Sustained working positions [54]

OR 1.61 (1.05 to 2.46$)$

Low work task variation [90]

RR 1.27 (1.08 to 1.50 )

Catastrophising [91]

WMD 6.6 (3.1 to 10.1$)$

Muscular tension (high perception) [54]

OR 4.04 (1.99 to 8.17)

Coworker support [54]

RR 2.43 (1.11 to 5.29)

History of neck pain [54]

OR 2.24 (1.39 to 3.06 )

High perception demands (work) [54]

RR 2.14 (1.28 to 3.58)

Stress [91]

OR 2.00 (1.50 to 2.70 )

Lower back pain [54]

RR 2.00 (1.60 to 2.40)

High role conflict [54]

OR 2.61 (1.09 to 6.21)

2nd year students (vs 1st year) [57]

OR $1.90(1.08$ to 3.35$)$

Employment status (ill/disabled) [54]

RR 1.90 (1.20 to 2.90)

Fair general health (status) [54]

RR 1.80 (1.30 to 2.60)

Muscular tension (medium perception) [54]

OR 1.79 (1.03 to 3.27 )

Effort-reward imbalance [54]

HR $1.66(1.16$ to 2.38$) \dagger$

Sleep (poor quality $/<$ sleep hours) [91]

OR 1.63 (1.23 to 2.18 )

Poor general health (status) [54]

OR 1.62 (1.07 to 2.44 )

Employment status (Part-time) [54]

RR 1.60 (1.20 to 2.20) 
Prior neck injury (vehicular accident) [56]

OR 2.3 (1.8 to 3.1$)$

Good resistance of the extensor muscles [54]

OR 0.92 (0.87 to 0.97$)$

Leisure physical activity [54]

OR $0.6(0.4$ to 0.9$)$

Pleasant social environment [54]

OR 0.45 (0.25 to 0.83$)$

Low satisfaction with workplace environment[90]

RR 1.28 (1.07 to 1.55 )

Leadership profile [54]

OR 0.32 (0.16 to 0.67$)$

$\mathrm{BMI}=$ Body mass index $; \mathrm{RR}=$ Risk ratios; HR: Hazard ratios; $\mathrm{WMD}=$ Weighted mean difference. Synthesis of evidence on risk factors in neck pain based on recent studies $[54,56,91]$. 
Table 2. Prognostic factors for patients with neck pain

\begin{tabular}{lll}
\hline Pain intensity & Odds ratio $(95 \%$ CI) & Quality of evidence \\
\hline Pain intensity - 3 months & $3.13(1.5$ to 6.67$)$ & Very low \\
Gender (male) & $0.74(0.57$ to 0.95$)$ & Very low \\
Severity of complaints (less) & $1.09(1.02$ to 1.15$)$ & Very low \\
Kinesiophobia (TSK) & & \\
Pain intensity - 12 months & $3.9(2.2$ to 6.7$)$ & Low \\
Age (45-59 years) & $1.6(1.1$ to 2.3$)$ & Very low \\
Not working & $2.4(1.5$ to 4.0$)$ & Very low \\
Cycling (regular activity) & $0.26(0.07 \text { to } 0.45)^{(\beta)}$ & Very low \\
Pain intensity at baseline & $1.6(1.1$ to 2.2$)$ & Very low \\
Low back pain & $1.35(0.34 \text { to } 1.93)^{(\beta)}$ & Very low \\
Neck pain (> 13 weeks) & $1.35(0.13 \text { to } 1.58)^{(\beta)}$ & Very low \\
Previous episodes of neck pain & &
\end{tabular}

Patient perceived non recovery

Patient perceived non recovery -3 months

Headache $\quad 3.70(1.47$ to 9.09$) \quad$ Low

Depression $\quad 1.30(1.02$ to 1.64$)$

Patient perceived non recovery - 6 months

$\begin{array}{lll}\text { Age (in years) } & 1.03(1.01 \text { to } 1.05) & \text { Very low } \\ \text { Low back pain } & 2.29(1.27 \text { to } 4.12) & \text { Low } \\ \text { Previous episodes of neck pain } & 1.67(1.25 \text { to } 2.24) & \text { Low }\end{array}$

Patient perceived non recovery -12 months

Gender (female)

4.55 (1.39 to 14.29$)$

Very low

Age (> 40 years)

3.85 (1.64 to 9.09$)$

Low

Low back pain

$2.7(1.25$ to 5.88$)$

Very low

$\mathrm{BMI}=$ Body mass index; $\mathrm{BQ}=$ The Bournemouth questionnaire; TSK = Tampa scale of Kinesiophobia, 4DSQ = Four dimensions psychological symptomatology questionnaire, $\beta$ $=$ Regression coefficient 95\% CI; Confidence interval estimate direction $(<$ better and $>$ poor prognosis). Synthesis of evidence on prognostic factors in non-specific neck pain conducted by Verwoerd [66] 
Table 3. Overview of the effects of interventions for neck pain on the outcome for short-term pain intensity.

\begin{tabular}{|c|c|c|c|c|}
\hline & $\begin{array}{l}\mathbf{N}^{0} \text { participants } \\
\text { (studies) }\end{array}$ & $\begin{array}{l}\text { Effect estimates } \\
(95 \% \mathrm{CI})\end{array}$ & Effect size & Quality of evidence \\
\hline \multicolumn{5}{|c|}{ Effects of interventions for acute and subacute neck pain } \\
\hline \multicolumn{5}{|l|}{ Pharmacological } \\
\hline $\begin{array}{l}\text { Intravenous intravenous methylprednisolone } \\
\text { (vs placebo) [82]* }\end{array}$ & 39 (1 trial) & $\begin{array}{l}\text { SMD -0.90 (-1.57 to - } \\
0.24)\end{array}$ & Large & - \\
\hline \multicolumn{5}{|l|}{ Nonpharmacological } \\
\hline $\begin{array}{l}\text { Manipulation alone of cervical region (vs } \\
\text { oral medication) [78] }\end{array}$ & $182(1$ trial $)$ & $\begin{array}{l}\text { SMD -0.34 (-0.64 to - } \\
0.05)\end{array}$ & - & Moderate \\
\hline $\begin{array}{l}\text { Manipulation alone of thoracic region (vs } \\
\text { inactive control) [78] }\end{array}$ & 242 (2 trials) & $\begin{array}{l}\text { SMD }-1.46(2.20 \text { to }- \\
0.71)\end{array}$ & - & Moderate \\
\hline $\begin{array}{l}\text { Patient education (educational video) (vs no } \\
\text { treatment)* [76] }\end{array}$ & $376(1$ trial $)$ & $\begin{array}{l}\text { SMD -0.67 (-0.87 to - } \\
0.46)\end{array}$ & - & Moderate \\
\hline $\begin{array}{l}\text { Patient education (self-care strategies) (vs } \\
\text { no treatment) [76] }\end{array}$ & 44 (1 trial) & SMD $0.09(-0.50$ to 0.68$)$ & - & Very low \\
\hline $\begin{array}{l}\text { Cognitive-behavioural therapy (vs other } \\
\text { interventions) [80] }\end{array}$ & 265 (3 trials) & $\begin{array}{l}\text { SMD -0.24 (-0.48 to } \\
0.00)\end{array}$ & - & Low quality \\
\hline Low-level laser therapy (vs placebo) [92] & 116 (2 trials) & RR $1.69(1.22$ to 2.33$)$ & - & - \\
\hline $\begin{array}{l}\text { Exercise (Stretching and strengthening) (vs } \\
\text { waiting list) [77] }\end{array}$ & 133 (1 trial) & $\begin{array}{l}\text { SMD -0.47 (-0.81 to - } \\
0.12)\end{array}$ & - & Low \\
\hline
\end{tabular}




\begin{tabular}{|c|c|c|c|c|}
\hline $\begin{array}{l}\text { Physiotherapy Intervention plus Extrinsic } \\
\text { Feedback (vs physiotherapy) [93] }\end{array}$ & 80 (2 trials) & $\begin{array}{l}\text { SMD -1.09 (-1.56 to - } \\
0.61)\end{array}$ & - & - \\
\hline $\begin{array}{l}\text { Active intervention (kinaesthetic and co- } \\
\text { ordination exercises plus regular exercises) } \\
\text { (vs regular exercises)* }[94]\end{array}$ & $66(1$ trial $)$ & $\begin{array}{l}\text { WMD } 0.40(-0.79 \text { to } \\
1.59)\end{array}$ & - & - \\
\hline \multicolumn{5}{|c|}{ Effects of interventions for subacute and chronic neck pain } \\
\hline \multicolumn{5}{|l|}{ Pharmacological } \\
\hline NSAIDs (vs placebo) [83] & 225 (2 trials) & MD -16.3 (-20.6 to -12$)$ & & Moderate \\
\hline Relaxation (vs minimal intervention) [95] & 393 (1 trial) & MD 20 (-40 to 80$)$ & - & - \\
\hline $\begin{array}{l}\text { Epidural injections (methylprednisolone and } \\
\text { lidocaine) (vs intramuscular methyl } \\
\text { prednisolone and lidocaine) [82] }\end{array}$ & $50(1$ trial $)$ & $\begin{array}{l}\text { SMD -1.46 (-2.16 to - } \\
0.76)\end{array}$ & Large & - \\
\hline Intramuscular injection & 3 trials & & - & - \\
\hline $\begin{array}{l}\text { Intramuscular lidocaine and neck } \\
\text { stretching (vs neck stretching) [82] }\end{array}$ & 1 trial & $\begin{array}{l}\text { SMD -1.36 (-1.93 to - } \\
\text { 0.80) }\end{array}$ & Large & - \\
\hline BoNT - A (vs placebo) [84] & $252(5$ trials $)$ & $\begin{array}{l}\text { SMD }-0.07(-0.36 \text { to } \\
0.21)\end{array}$ & & High \\
\hline Nonpharmacological & & & & \\
\hline Massage (vs sham laser) [81] & $106(1$ trial $)$ & SMD $-0.01(-0.38$ to 0.36$)$ & - & Very low \\
\hline $\begin{array}{l}\text { Manipulation and mobilization (vs inactive } \\
\text { control) }[78]\end{array}$ & 111 (1 trial) & $\begin{array}{l}\text { SMD -0.64 (-1.04 to - } \\
0.25)\end{array}$ & Medium & Low \\
\hline
\end{tabular}


Patient education (vs no treatment) [76]

Cognitive-behavioural therapy (vs no

treatment) [80]

Acupuncture (vs medication) [96]

Dry needling (vs other interventions) [97]

Electrotherapy - Magnetic necklaces

(vs placebo) [79]

Electrotherapy - EMS (vs placebo) [79]

Transcutaneous electrical nerve stimulation

(TENS) (vs sham) [98]

Mechanical traction (vs placebo) [75]

Motor control (vs other interventions) [85]

Exercises (vs waiting list) [77]

$$
\begin{aligned}
& 46 \text { (1 trial) } \\
& 99 \text { (3 trials) }
\end{aligned}
$$

30 (1 trial)

107 (2 trials)

52 (1 trial)

40 (1 trial)

38 (1 trial)

$$
\begin{aligned}
& 84 \text { (1 trial) } \\
& 96 \text { (2 trials) }
\end{aligned}
$$

147 (2 trials)
SMD 0.09 (-0.49 to 0.67) -

SMD -0.58 (-1.01 to - $\quad$ Medium

0.16)

SMD 0.23 (-95 to 0.48$)$

SMD 0.01 (-0.41 to 0.40$)$

SMD $0.27(-0.27$ to 0.82$)$

SMD -0.36 (-0.99 to 0.27)

MD -1 (-9.7 to 7.7$)$

SMD -0.16 (-0.59 to 0.27)

SMD -0.33 (-0.73 to 0.08$)$

MD -14.90 (-22.40 to - Medium
Very low

Low

Moderate

-

Low

Very low

Very low

Low

Low

Moderate

7.39)

Information extracted preferably from Cochrane reviews for the outcome pain intensity (0-100 points) at short-term follow-up (equal to or less than three months). Effect estimates on pain scale from 0 to 10 points were converted to 100-point scales. Results in bold represents significant differences between groups. Evaluation of the quality of the evidence was carried out using the Grading of Recommendations Assessment, Development and Evaluation (GRADE) (with level of evidence from very low to high) if available by the author review.

SMD: Standardised Mean Difference; MD: Mean Difference; WMD: Weight Mean Difference; NSAIDs: Nonsteroidal anti-inflammatory drugs; BoNT-A: Botulinum toxin type A; EMS: Electric muscle stimulation. * Whiplash patients 


\section{References}

1. Vos T, Allen C, Arora M et al. Global, regional, and national incidence, prevalence, and years lived with disability for 310 diseases and injuries, 1990-2015: a systematic analysis for the Global Burden of Disease Study 2015. The Lancet 388(10053), 1545-1602 (2016).

2. Fejer R, Kyvik KO, Hartvigsen J. The prevalence of neck pain in the world population: a systematic critical review of the literature. Eur Spine J 15(6), 834-848 (2006).

3. Safiri S, Kolahi AA, Hoy D et al. Global, regional, and national burden of neck pain in the general population, 1990-2017: systematic analysis of the Global Burden of Disease Study 2017. BMJ 368 m791 (2020).

4. Hoy DG, Protani M, De R, Buchbinder R. The epidemiology of neck pain. Best Pract Res Clin Rheumatol 24(6), 783-792 (2010).

5. Hush JM, Michaleff Z, Maher CG, Refshauge K. Individual, physical and psychological risk factors for neck pain in Australian office workers: a 1-year longitudinal study. European spine journal : official publication of the European Spine Society, the European Spinal Deformity Society, and the European Section of the Cervical Spine Research Society 18(10), $1532-1540$ (2009).

6. Côté P, Van Der Velde G, Cassidy JD et al. The burden and determinants of neck pain in workers: results of the Bone and Joint Decade 2000-2010 Task Force on Neck Pain and Its Associated Disorders. Spine (Phila Pa 1976) 33(4 Suppl), S60-74 (2008).

7. De Cassia Pereira Fernandes R, Pataro SMS, De Carvalho RB, Burdorf A. The concurrence of musculoskeletal pain and associated work-related factors: a cross sectional study. BMC Public Health 16628 (2016). 
8. Sarquis LM, Coggon D, Ntani G et al. Classification of neck/shoulder pain in epidemiological research: a comparison of personal and occupational characteristics, disability, and prognosis among 12,195 workers from 18 countries. Pain 157(5), 1028-1036 (2016).

9. Haldeman S, Carroll L, Cassidy JD, Schubert J, Nygren A. The Bone and Joint Decade 2000-2010 Task Force on Neck Pain and Its Associated Disorders. European Spine Journal 17(S1), 5-7 (2008).

10. Hoy D, March L, Woolf A et al. The global burden of neck pain: estimates from the global burden of disease 2010 study. Annals of the rheumatic diseases 73(7), 1309-1315 (2014).

11. Jette AM, Smith K, Haley SM, Davis KD. Physical therapy episodes of care for patients with low back pain. Phys Ther 74(2), 101-110; discussion 110-105 (1994).

12. Dieleman JL, Cao J, Chapin A et al. US Health Care Spending by Payer and Health Condition, 1996-2016. JAMA 323(9), 863-884 (2020).

13. Blanpied Pr, Gross Ar, Elliott Jm et al. Neck Pain Revision 2017. Journal of Orthopaedic \& Sports Physical Therapy 47(7), A1-A83 (2017).

14. Guzman J, Hurwitz EL, Carroll LJ et al. A new conceptual model of neck pain: linking onset, course, and care: the Bone and Joint Decade 2000-2010 Task Force on Neck Pain and Its Associated Disorders. Spine (Phila Pa 1976) 33(4 Suppl), S14-23 (2008).

15. Cohen $\mathrm{Sp}, \mathrm{Wm} \mathrm{H}$. Advances in the diagnosis and management of neck pain. Bmj 358 j3221 (2017).

16. Childs JD, Cleland JA, Elliott JM et al. Neck pain: Clinical practice guidelines linked to the International Classification of Functioning, Disability, and Health from the Orthopedic 
Section of the American Physical Therapy Association. The Journal of orthopaedic and sports physical therapy 38(9), A1-A34 (2008).

17. Bier JD, Scholten-Peeters WGM, Staal JB et al. Clinical Practice Guideline for Physical Therapy Assessment and Treatment in Patients With Nonspecific Neck Pain. Phys Ther 98(3), 162-171 (2018).

18. Borghouts JA, Koes BW, Bouter LM. The clinical course and prognostic factors of nonspecific neck pain: a systematic review. Pain 77(1), 1-13 (1998).

19. Michaleff ZA, Ferreira ML. Physiotherapy rehabilitation for whiplash associated disorder II: a systematic review and meta-analysis of randomised controlled trials. British journal of sports medicine 46(9), 662-663 (2012).

20. Anderson C, Yeung E, Toong T, Tong T, Reed N. A narrative review on cervical interventions in adults with chronic whiplash-associated disorder. BMJ Open Sport Exerc Med 4(1), e000299 (2018).

21. Spitzer WO, Skovron ML, Salmi LR et al. Scientific monograph of the Quebec Task Force on Whiplash-Associated Disorders: redefining "whiplash" and its management. Spine 20(8 Suppl), 1S-73S (1995).

22. Spitzer WO, Skovron ML, Salmi LR et al. Scientific monograph of the Quebec Task Force on Whiplash-Associated Disorders: redefining "whiplash" and its management. Spine 20(8 Suppl), 1S-73S (1995).

23. Maissan F, Pool J, De Raaij E, Wittink H, Ostelo R. Treatment based classification systems for patients with non-specific neck pain. A systematic review. Musculoskelet Sci Pract 47102133 (2020). 
24. Michaleff ZA, Maher CG, Verhagen AP, Rebbeck T, Lin CW. Accuracy of the Canadian C-spine rule and NEXUS to screen for clinically important cervical spine injury in patients following blunt trauma: a systematic review. CMAJ : Canadian Medical Association journal = journal de l'Association medicale canadienne 184(16), E867-876 (2012).

25. Saragiotto BT, Michaleff ZA. The Canadian C-Spine Rule. Journal of physiotherapy 62(3), 170 (2016).

26. Nordin M, Carragee EJ, Hogg-Johnson S et al. Assessment of neck pain and its associated disorders: results of the Bone and Joint Decade 2000-2010 Task Force on Neck Pain and Its Associated Disorders. Spine (Phila Pa 1976) 33(4 Suppl), S101-122 (2008).

27. Goergen S VD, Ackland H, Michaleff Z, Rosenfeld Jv, Malham G, Johnson S, Rahman T. Adult Cervical Spine Trauma. Education Modules for Appropriate Imaging Referrals:. Royal Australian and New Zealand College of Radiologists;, (2015).

28. Kanwar R, Delasobera BE, Hudson K, Frohna W. Emergency department evaluation and treatment of cervical spine injuries. Emerg Med Clin North Am 33(2), 241-282 (2015).

29. Expert Panel on Neurological I, Mcdonald MA, Kirsch CFE et al. ACR Appropriateness Criteria((R)) Cervical Neck Pain or Cervical Radiculopathy. J Am Coll Radiol 16(5S), S57-S76 (2019).

30. Popescu A, Lee H. Neck Pain and Lower Back Pain. Med Clin North Am 104(2), 279$292(2020)$.

31. Kettler A, Werner K, Wilke HJ. Morphological changes of cervical facet joints in elderly individuals. European spine journal : official publication of the European Spine Society, the European Spinal Deformity Society, and the European Section of the Cervical Spine Research Society 16(7), 987-992 (2007). 
32. Matsumoto $\mathrm{M}$, Fujimura $\mathrm{Y}$, Suzuki $\mathrm{N}$ et al. MRI of cervical intervertebral discs in asymptomatic subjects. J Bone Joint Surg Br 80(1), 19-24 (1998).

33. Nakashima H, Yukawa Y, Suda K, Yamagata M, Ueta T, Kato F. Abnormal findings on magnetic resonance images of the cervical spines in 1211 asymptomatic subjects. Spine (Phila Pa 1976) 40(6), 392-398 (2015).

34. Okada $E$, Matsumoto $M$, Ichihara $D$ et al. Does the sagittal alignment of the cervical spine have an impact on disk degeneration? Minimum 10-year follow-up of asymptomatic volunteers. European spine journal : official publication of the European Spine Society, the European Spinal Deformity Society, and the European Section of the Cervical Spine Research Society 18(11), 1644-1651 (2009).

35. Lehto IJ, Tertti MO, Komu ME, Paajanen HE, Tuominen J, Kormano MJ. Age-related MRI changes at $0.1 \mathrm{~T}$ in cervical discs in asymptomatic subjects. Neuroradiology 36(1), 49-53 (1994).

36. Machino M, Yukawa Y, Imagama S et al. Age-Related and Degenerative Changes in the Osseous Anatomy, Alignment, and Range of Motion of the Cervical Spine: A Comparative Study of Radiographic Data From 1016 Patients With Cervical Spondylotic Myelopathy and 1230 Asymptomatic Subjects. Spine (Phila Pa 1976) 41(6), 476-482 (2016).

37. Kato F, Yukawa Y, Suda K, Yamagata M, Ueta T. Normal morphology, age-related changes and abnormal findings of the cervical spine. Part II: Magnetic resonance imaging of over 1,200 asymptomatic subjects. European spine journal : official publication of the European Spine Society, the European Spinal Deformity Society, and the European Section of the Cervical Spine Research Society 21(8), 1499-1507 (2012).

38. Blasini M, Corsi N, Klinger R, Colloca L. Nocebo and pain: An overview of the psychoneurobiological mechanisms. Pain Rep 2(2), (2017). 
39. Chiarotto A, Deyo RA, Terwee CB et al. Core outcome domains for clinical trials in non-specific low back pain. European spine journal : official publication of the European Spine Society, the European Spinal Deformity Society, and the European Section of the Cervical Spine Research Society 24(6), 1127-1142 (2015).

40. Chiarotto A, Ostelo RW, Turk DC, Buchbinder R, Boers M. Core outcome sets for research and clinical practice. Braz J Phys Ther 21(2), 77-84 (2017).

41. Chiarotto A, Boers M, Deyo RA et al. Core outcome measurement instruments for clinical trials in nonspecific low back pain. Pain 159(3), 481-495 (2018).

42. Young la Pt D, Dunning J Pt DPT, Butts R Pt P, Mourad F Pt DPT, Cleland Ja Pt P. Reliability, construct validity, and responsiveness of the neck disability index and numeric pain rating scale in patients with mechanical neck pain without upper extremity symptoms. Physiotherapy theory and practice 35(12), 1328-1335 (2019).

43. Young IA, Cleland JA, Michener LA, Brown C. Reliability, construct validity, and responsiveness of the neck disability index, patient-specific functional scale, and numeric pain rating scale in patients with cervical radiculopathy. American journal of physical medicine \& rehabilitation 89(10), 831-839 (2010).

44. Young IA, Dunning J, Butts R, Cleland JA, Fernández-De-Las-Peñas C. Psychometric properties of the Numeric Pain Rating Scale and Neck Disability Index in patients with cervicogenic headache. Cephalalgia : an international journal of headache 39(1), 44-51 (2019).

45. Schellingerhout JM, Verhagen AP, Heymans MW, Koes BW, De Vet HC, Terwee CB. Measurement properties of disease-specific questionnaires in patients with neck pain: a systematic review. Qual Life Res 21(4), 659-670 (2012). 
46. Lemeunier N, Da Silva-Oolup S, Olesen K et al. Reliability and validity of self-reported questionnaires to measure pain and disability in adults with neck pain and its associated disorders: part 3-a systematic review from the CADRE Collaboration. European spine journal : official publication of the European Spine Society, the European Spinal Deformity Society, and the European Section of the Cervical Spine Research Society 28(5), 1156-1179 (2019).

47. Snaith RP. The Hospital Anxiety And Depression Scale. Health Qual Life Outcomes 1 29 (2003).

48. Cosco TD, Doyle F, Ward M, Mcgee H. Latent structure of the Hospital Anxiety And Depression Scale: a 10-year systematic review. J Psychosom Res 72(3), 180-184 (2012).

49. Sullivan MJL, Bishop S, Pivik J. The Pain Catastrophizing Scale: Development and Validation. Psychological Assessment 7 524-532 (1996).

50. Hudes K. The Tampa Scale of Kinesiophobia and neck pain, disability and range of motion: a narrative review of the literature. J Can Chiropr Assoc 55(3), 222-232 (2011).

51. Montazeri A, Vahdaninia M, Mousavi SJ, Asadi-Lari M, Omidvari S, Tavousi M. The 12item medical outcomes study short form health survey version 2.0 (SF-12v2): a populationbased validation study from Tehran, Iran. Health Qual Life Outcomes 912 (2011).

52. Kularatna S, Whitty JA, Johnson NW, Jayasinghe R, Scuffham PA. EQ-5D-3L derived population norms for health related quality of life in Sri Lanka. PLoS One 9(11), e108434 (2014).

53. Song $C-Y$, Lin S-F, Huang $C-Y$, Wu H-C, Chen C-H, Hsieh C-L. Validation of the Brief Pain Inventory in Patients With Low Back Pain. Spine 41 (2016).

54. Kim R, Wiest C, Clark K, Cook C, M. H. Identifying risk factors for first-episode neck pain: A systematic review. Musculoskelet Sci Pract 33 77-83 (2018). 
55. Taylor Jb, Goode Ap, George Sz, Ce. C. Incidence and risk factors for first-time incident low back pain: a systematic review and meta-analysis. The spine journal : official journal of the North American Spine Society 14(10), 2299-2319 (2014).

56. Nolet Ps, Emary Pc, Kristman VI, Murnaghan K, Zeegers Mp, Md F. Exposure to a Motor Vehicle Collision and the Risk of Future Neck Pain: A Systematic Review and MetaAnalysis. PM \& $R$ : the journal of injury, function, and rehabilitation 11(11), 1228-1239 (2019).

57. Jahre H, Grotle M, Smedbråten K, Dunn Km, Øiestad Be. Risk factors for non-specific neck pain in young adults. A systematic review. BMC musculoskeletal disorders 21(1), 366 (2020).

58. Hush Jm, Lin Cc, Michaleff Za, Verhagen A, Refshauge Km. Prognosis of acute idiopathic neck pain is poor: a systematic review and meta-analysis. Arch Phys Med Rehabil 92(5), 824-829 (2011).

59. Walton Dm, Carroll Lj, Kasch $\mathrm{H}$ et al. An Overview of Systematic Reviews on Prognostic Factors in Neck Pain: Results from the International Collaboration on Neck Pain (ICON) Project. The open orthopaedics journal 7 494-505 (2013).

60. Vos Cj, Verhagen Ap, Passchier J, Koes Bw. Clinical course and prognostic factors in acute neck pain: an inception cohort study in general practice. Pain medicine (Malden, Mass.) 9(5), 572-580 (2008).

61. Carroll Lj, Hogg-Johnson S, Van Der Velde G et al. Course and Prognostic Factors for Neck Pain in the General Population Results of the Bone and Joint Decade 2000-2010 Task Force on Neck Pain and Its Associated. Journal of manipulative and physiological therapeutics 32(2 Suppl), S87-96 (2009). 
62. Vasseljen O, Woodhouse A, Bjørngaard Jh, Leivseth L. Natural course of acute neck and low back pain in the general population The HUNT study. Pain 154(8), 1237-1244. (2013).

63. Hill J, Lewis M, Papageorgiou Ac, Dziedzic K, Croft P. Predicting persistent neck pain: a 1-year follow-up of a population cohort. Spine (Phila Pa 1976) 29(15), 1648-1654 (2004).

64. Hoving Jl, De Vet Hc, Twisk Jw et al. Prognostic factors for neck pain in general practice. Pain 110(3), 639-645 (2004).

65. Pool Jj, Ostelo Rw, Knol D, Bouter Lm, De Vet Hc. Are psychological factors prognostic indicators of outcome in patients with sub-acute neck pain? Man Ther 15(1), 111-116 (2010).

66. Verwoerd M, Wittink H, Maissan F, De Raaij E, Smeets Rjem. Prognostic factors for persistent pain after a first episode of nonspecific idiopathic, non-traumatic neck pain: A systematic review. Musculoskelet Sci Pract 42 13-37 (2019).

67. Coronavirus. Coronavirus disease (COVID-19) pandemic. 2020(28/05/2020), (2020).

68. Driessen Mt, Proper Ki, Anema Jr, Knol DI, Bongers Pm, Van Der Beek Aj. The effectiveness of participatory ergonomics to prevent low-back and neck pain - results of a cluster randomized controlled trial. Scandinavian Journal of Work, Environment \& Health (5), 383-393 (2011).

69. Sihawong R, Janwantanakul P, Jiamjarasrangsi W. Effects of an exercise programme on preventing neck pain among office workers: a 12-month cluster-randomised controlled trial. Occupational and environmental medicine 71(1), 63-70 (2014).

70. Sitthipornvorakul E, R. S. The effects of walking intervention on preventing neck pain in office workers: A randomized controlled trial. (2019). 
71. De Campos Tf, Maher Cg, Steffens D, Fuller Jt, Hancock Mj. Exercise programs may be effective in preventing a new episode of neck pain: a systematic review and meta-analysis. $J$ Physiother 64(3), 159-165 (2018).

72. Soler-Font M, Ramada Jm, Van Zon Skr, Almansa J, Bultmann U, C. S. Multifaceted intervention for the prevention and management of musculoskeletal pain in nursing staff: Results of a cluster randomized controlled trial. PLoS One 14(11), e0225198 (2019).

73. Bier J, Scholten-Peeters Gg, M. Staal Jb et al. KNGF Guideline Neck Pain. Royal Dutch Society for Physical Therapy (2016).

74. Monticone M, lovine R, Sena G et al. The Italian Society of Physical and Rehabilitation Medicine (SIMFER) recommendations for neck pain. G Ital Med Lav Ergon 35 36-50 (2013).

75. Graham N, Gross A, Goldsmith Ch et al. Mechanical traction for neck pain with or without radiculopathy. Cochrane Database of Systematic Reviews (3), (2008).

76. Gross A, Forget M, St George K et al. Patient education for neck pain. Cochrane Database of Systematic Reviews 4 (2012).

77. Gross A, Kay Tm, Paquin Jp et al. Exercises for mechanical neck disorders Cochrane Database of Systematic Reviews (1), (2015).

78. Gross A, Langevin P, Burnie Sj et al. Manipulation and mobilisation for neck pain contrasted against an inactive control or another active treatment. The Cochrane database of systematic reviews (9), Cd004249 (2015).

79. Kroeling P, Gross A, Graham N et al. Electrotherapy for neck pain Cochrane Database of Systematic Reviews (8), 1-103 (2013). 
80. Monticone M, Cedraschi C, Ambrosini E et al. Cognitive-behavioural treatment for subacute and chronic neck pain. Cochrane Database of Systematic Reviews (5), CD010664 (2015).

81. Patel Kc, Gross A, Graham N et al. Massage for mechanical neck disorders. Cochrane Database of Systematic Reviews (9), (2012).

82. Peloso Pmj, Gross A, Haines T, Trinh K, Goldsmith Ch, Burnie Sj. Medicinal and injection therapies for mechanical neck disorders. Cochrane Database of Systematic Reviews (3), (2007).

83. Machado Gc, Maher Cg, Ferreira Ph, Day Ro, Pinheiro Mb, Ferreira Ml. Non-steroidal anti-inflammatory drugs for spinal pain: a systematic review and meta-analysis. Annals of the Rheumatic Diseases 76 1269-1278 (2017).

84. Langevin P, Peloso Pmj, Lowcock J et al. Botulinum toxin for subacute/chronic neck pain. Cochrane Database of Systematic Reviews (7), (2011).

85. Martin-Gomez C, Sestelo-Diaz R, Carrillo-Sanjuan V, Navarro-Santana Mj, BardonRomero J, Plaza-Manzano G. Motor control using cranio-cervical flexion exercises versus other treatments for non-specific chronic neck pain: A systematic review and meta-analysis. Musculoskelet Sci Pract 42 52-59 (2019).

86. Herbert R JG, Mead J, Hagen Kb. Practical Evidence-Based Physiotherapy. (2005).

87. Mota Da Silva T, Da Cunha Menezes Costa LO, Garcia AN, Costa LOP. What do physical therapists think about evidence-based practice? A systematic review. Manual Therapy 20(3), 388-401 (2015). 
88. Silva Tm, Costa Lc, Lo. C. Evidence-Based Practice: a survey regarding behavior, knowledge, skills, resources, opinions and perceived barriers of Brazilian physical therapists from Sao Paulo state. Brazilian Journal of Physical Therapy 19(4), 294-303 (2015).

89. Silva Pv, Costa Lop, Maher Cg, Sj K, Lop C. The New Agenda for Neck Pain Research: A Modified Delphi Study. Journal of Orthopaedic \& Sports Physical Therapy 49(9), 666-674 (2019).

90. Jun D, Zoe M, Johnston V, O'leary S. Physical risk factors for developing non-specific neck pain in office workers: a systematic review and meta-analysis. Int Arch Occup Environ Health 90(5), 373-410 (2017).

91. Andias R, Ag S. Psychosocial Variables and Sleep Associated With Neck Pain in Adolescents: A Systematic Review. Physical \& Occupational Therapy Pediatrics 40(2), 168$191(2020)$.

92. Chow Rt, Johnson Mi, Lopes-Martins Ra, Bjordal Jm. Efficacy of low-level laser therapy in the management of neck pain: a systematic review and meta-analysis of randomised placebo or active-treatment controlled trials. Lancet 374(9705), 1897-1908 (2009).

93. Araujo Fx, Scholl Sm, Ribeiro Dc. Effectiveness of Physiotherapy interventions plus Extrinsic Feedback for neck disorders: A systematic review with meta-analysis. Musculoskelet Sci Pract 29 132-143 (2017).

94. Verhagen Ap, Scholten-Peeters G, Van Wijngaarden S, De Bie R, Bierma-Zeinstra Sma. Conservative treatments for whiplash. Cochrane Database of Systematic Reviews (2), (2007).

95. Leaver Am, Refshauge $\mathrm{Km}$, Maher $\mathrm{Cg}$, Mcauley Jh. Conservative interventions provide short-term relief for non-specific neck pain: a systematic review. J Physiother 56(2), 73-85 (2010). 
96. Seo Sy, Lee Kb, Shin Js et al. Effectiveness of Acupuncture and Electroacupuncture for Chronic Neck Pain: A Systematic Review and Meta-Analysis. The American journal of Chinese medicine 45(8), 1573-1595 (2017).

97. Liu L, Huang Qm, Liu Qg et al. Effectiveness of dry needling for myofascial trigger points associated with neck and shoulder pain: a systematic review and meta-analysis. Arch Phys Med Rehabil 96(5), 944-955 (2015).

98. Martimbianco Alc, Porfírio Gjm, Pacheco RI, Torloni Mr, Riera R. Transcutaneous electrical nerve stimulation (TENS) for chronic neck pain. Cochrane Database of Systematic Reviews (12), (2019). 